\title{
From awareness to action on the social determinants of health
}

\author{
Spencer Moore
}

Published online: 5 May 2010

(C) Swiss School of Public Health 2010

The following editorial continues the series of editorials in the International Journal of Public Health on the WHO Commission Report on the Social Determinants of Health (CSDH, WHO 2008; Siegrist 2008; Vågerö 2008; McQueen 2009; Koskinen and Puska 2009; Potvin 2009; MadarasovaGeckova 2009). In its final principle of action, the WHO Commission (CSDH) recognized the need to raise public awareness of the social determinants of health. Raised awareness should consist, according to the report, of a better understanding among actors, practitioners, and the general public of how population health is affected by social determinants (WHO 2008). Raised awareness may be the first step on a long path to action on the social determinants of health ultimately improving the public's capacity for action (Madarasova-Geckova 2009). Yet, to close the gap will require more than raised awareness, it will require community-based action in a variety of forms. To contribute more broadly to the development of diverse communitybased initiatives in addressing the social determinants of

Spencer Moore is Assistant Professor in the School of Kinesiology and Health Studies at Queen's University, Kingston, Ontario, and Researcher at the centre de recherche du Centre Hospitalier de l'Université de Montréal. He also holds a New Investigator Award from the Institute of Aging of the Canadian Institutes of Health Research.

This Editorial belongs to the series "Social determinants of health".

S. Moore $(\bowtie)$

School of Kinesiology and Health Studies, Queen's University,

Kingston K7L3N6, Canada

e-mail: mooresp@queensu.ca

S. Moore

centre de recherche du Centre Hospitalier de l'Université de

Montréal, Montreal, Canada health, the CSDH could have recognized a wider range of health promotion strategies within the report.

Within the health promotion literature, there are a range of approaches and strategies for considering how to facilitate group and community willingness to address the social determinants of health. These range from more cooperative and collaborative models to those that assume more of a political conflict perspective. The relevance and appropriateness of specific approaches and strategies are context specific, and there is no one size that fits all. With these ideas in mind, it is worth considering certain assumptions about community action favored within the report. The CSDH report assumes that raised awareness about the social determinants of health will lead politicians and community groups to cooperate and work together in bringing about change. Using the analogy of a "nutcracker effect," the commission describes the cracking of health inequity as coming from the cooperative action and joint pressure of top-down policy making and bottom-up community action (WHO 2008).

To what degree does raised awareness translate into action? At the community level, research is mixed in support of this assumption. In Canada, an association between individual recognition of the structural causes of health inequities and a person's willingness to support social policies to address those inequalities has been found Reutter et al. 2002). In the United States, however, it was recently shown that a person's receptivity to a message on the social determinants of health is conditioned in part by their prior political beliefs (Gollust et al. 2009). After being exposed to a social determinants framing on a message about diabetes, Democrats expressed a higher level of support for public health policies, while Republicans expressed a lower level (Gollust et al. 2009). Advocates seeking to mobilize broad public support to address health 
inequities will need to recognize that the public is not a tabula rasa, and that public health messages about the social determinants of health may need to be tailored to specific groups within society.

At the policy level, there is also reason to be skeptical of the assumption that raised awareness alone will lead to change. Research has suggested that policymakers should be the primary targets of campaigns to raise awareness on the social determinants of health since their views, as opposed to the views of specific constituencies, tend to shape the final form of policies (Bartels et al. 2005; Neiderdeppe et al. 2008). Yet, political leaders tend to come from higher socioeconomic groups in society and may feel no personal stake in policy outcomes (Neiderdeppe et al. 2008). Raising awareness of the social determinants of health among political elites may ultimately involve, as Neiderdeppe et al. have argued, the difficult challenge of convincing higher socioeconomic groups to forego their own self interest and consider the plight and circumstances of low socioeconomic groups in formulating policy (Neiderdeppe et al. 2008). Even under those conditions in which increased awareness has occurred among policymakers, there will be a failure to influence behavior, specifically policy change, if supporting structures are not in place to enable, reinforce, or push for change (Green and Kreuter 2005).

Implicit in what Green and Kreuter (2005) have referred to as the "power-educative approach" is the possibility of bad publicity or conflict, in the form of legal action or boycotts, if policy change does not take place. While the CSDH's use of the nutcracker analogy is appealing, particularly given its collaborative sentiment, absent in its use is recognition of the supporting structures that need to be in place to force action. These structures are not likely present in all countries in the same manner. Indeed, in an independent publication, Dr. Fran Baum, one of the SDH Commissioners, suggested that topdown and bottom-up pressure for change will likely stand more success in countries with high levels of linking social capital (Baum 2007). Linking social capital refers to norms of respect and trust between people who are interacting across formal, institutionalized structures of authority (Baum 2007). Unfortunately, many of the upstream social determinants that influence health are also likely to influence a country's level of linking social capital. As a result, it may be the case that those places with the highest levels of health inequity will also be those with the lowest levels of linking social capital. If action on the SHD is going to occur in such contexts, community groups and activists will need to rely on a broad set of strategies and approaches for addressing the gap in health equity.

To move beyond awareness and onto action requires recognition and use of the full range of community organizing strategies. Such strategies include community-based social action and organizing that brings grassroots pressure to bear on politicians and the state (Fisher 1999).
Globalization is characterized not only by increased capital mobility and privatization of common resources, but also the weakening of state institutions. Nevertheless, state institutions remain critical targets for social action campaigns (Fisher 1999). Tackling the inequitable distribution of power, money, and resources is as likely to engender conflict as cooperation. Those with power and resources do not often look to share or lose them (Vågerö 2008). Conflict need not be violent, but the assumption that change will take place smoothly through regular policy and institutional channels requires careful interrogation. Greater recognition in the report of the need for creative, multiple, and diverse community-based strategies, including organized confrontation, e.g., consumer boycotts, strikes, petitions, or legal action, might help legitimate the efforts of those communities where more cooperative approaches have not taken hold.

\section{References}

Bartels LM, Heclo H, Hero RE, Jacobs LR (2005) Inequality and American Governance. In: Jacobs LR, Skocpol T (eds) Inequality and American Democracy: what we know and what we need to learn. Russel Sage, New York, pp 88-155

Baum F (2007) Cracking the nut of health equity: top down and bottom up pressure for action on the social determinants of health. Promot Educ 14(2):90-95

Fisher R (1999) Social action community organization. In: Minkler M (ed) Community organizing and community building for health. Rutgers University Press, USA, pp 53-67

Gollust SE, Lantz P, Ubel P (2009) The polarizing effect of news media messages about the social determinants of health. Am J Public Health 99(12):2160-2167

Green L, Kreuter MW (2005) Health program planning. McGraw Hill, Boston

Koskinen S, Puska P (2009) From social determinants to reducing health inequalities. Int J Public Health 54:53-54

Madarasova-Geckova A (2009) Can research contribute to the public's capacity for activities that reduce socioeconomic inequalities in health? Int J Public Health 54:201-202

McQueen D (2009) Three challenges for the social determinants of health pursuit. Int J Public Health 54:1-2

Neiderdeppe J, Bu QL, Borah P, Kindig D, Robert SA (2008) Message design strategies to raise public awareness of social determinants of health and population health disparities. Milbank Q 86(3):481-513

Potvin L (2009) Yes! More research is needed; but not just any research. Int J Public Health 54:127-128

Reutter LI, Harrison MJ, Neufeld A (2002) Public support for poverty-related policies. Can J Public Health 93(4):297-302

Siegrist J (2008) Social determinants of health-a cross-cultural perspective. Int J Public Health 53:277-278

Vågerö D (2008) Closing the global health gaps in a generation-how is it possible? Int J Public Health 53:279-280

WHO (2008) Closing the gap in a generation: health equity through action on the social determinants of health. Final report of the commission on social determinants of health. World Health Organization, Geneva. Available at http://www.who.int/social_ determinants/final_report/en/. Accessed 15 Oct 2009 